\title{
Hydrodeoxygenation of Vegetable Oil in a Trickle Bed Reactor for Renewable Diesel Production
}

\author{
Yuswan Muharam $^{1 *}$, Jessica Adeline Soedarsono ${ }^{1}$ \\ ${ }^{1}$ Department of Chemical Engineering, Faculty of Engineering, Universitas Indonesia, Kampus UI Depok, \\ Depok 16424, Indonesia
}

\begin{abstract}
The hydrodeoxygenation of vegetable oil in a trickle bed reactor for renewable diesel production was observed in this research. Vegetable oil was represented by triolein. The $\mathrm{NiMo} / \mathrm{Al}_{2} \mathrm{O}_{3}$ catalyst with a composition of $6.13 \% \mathrm{w} / \mathrm{w} \mathrm{Ni}, 12.49 \% \mathrm{w} / \mathrm{w} \mathrm{Mo}$, and $81.33 \% \mathrm{w} / \mathrm{w} \mathrm{Al}_{2} \mathrm{O}_{3}$ was used. The reactions took place in the temperature range of $272-327.5^{\circ} \mathrm{C}$ and pressures of 5 and 15 bar. A trickle bed reactor of $2.01 \mathrm{~cm}$ in diameter and $24 \mathrm{~cm}$ in bed length was able to convert triolein into renewable diesel. $\mathrm{C}_{18}$ hydrocarbons became the dominant reacting compounds at temperatures above $310^{\circ} \mathrm{C}$ and a pressure of $15 \mathrm{bar}$, which reached more than $50 \% \mathrm{w} / \mathrm{w}$. At $5 \mathrm{bar}$ pressure, fatty acids with stearic acid as the acid with the highest concentration were the dominant reacting component, reaching more than $60 \% \mathrm{w} / \mathrm{w}$ at temperatures above $280^{\circ} \mathrm{C}$. This led to double bond saturation once the reactants were mixed.
\end{abstract}

Keywords: Hydrodeoxygenation; Renewable diesel; Trickle bed reactor

\section{Introduction}

The Fuel is one of the basic needs for transportation and industry, which mostly comes from petroleum processing (fossil-based). Economic oil reserves are depleting, while energy demand continues to increase with population size and advancing technology. Moreover, fossil fuel produces a high content of carbon dioxide in its combustion (Pinzi and Dorado, 2012). Currently, the world consumes around 13 TW of energy each year, and 80\% of it is obtained from fossil fuels. Seeing the energy demand and opportunity of the chemical industry's rapid growth in converting hydrocarbon into chemical products, it was projected that in the future, the energy sector will be dominated by renewable fuel. In 2030, renewable fuel is targeted to increase four times compared to that in 2010 (Douvartzides et al., 2019).

Furthermore, renewable fuel is more environmentally friendly in terms of emissions. Currently, renewable diesel is one of the most rapidly developed renewable resources since its characteristics are similar to petrodiesel, and its cetane number is high. It consists of straight-chain alkanes in the range of diesel fuel $\left(\mathrm{C}_{15}-\mathrm{C}_{18}\right)$. In addition to its advantages, the cost to produce renewable diesel is becoming more competitive with that of fossil fuels. This shows that shifting from fossil fuel domination to renewable energy will indirectly

*Corresponding author's email: muharam@che.ui.id,, Tel.: +62-812-94634399

doi: 10.14716/ijtech.v11i7.4491 
have a positive economic impact (Setiawan and Asvial, 2016).

Renewable diesel is produced from vegetable oil. Triglycerides are the main component of vegetable oil, but its high viscosity and instability requires it to be treated before use. Among all processes, hydrotreating is the most advanced method from the point of view of technology and research due to its product characteristics and ability to utilize existing systems in oil refinery (Holmgren, 2007).

In hydrotreating, vegetable oil as a feed reacts with hydrogen gas. Hydrogen binds with oxygen in the triglyceride; therefore, it is called hydrodeoxygenation and produces alkanes with the same carbon number as its feed. Catalysts with active sites of nickel and molybdenum are frequently used (Kubička et al., 2010; Bezergianni and Dimitriadis, 2013). However, most research favors using molybdenum as an active site, such as that by Gong et al. (2012). They carried out hydrodeoxygenation using vegetable oil with a $\mathrm{NiMoP} / \mathrm{Al}_{2} \mathrm{O}_{3}$ catalyst and molybdenum as an active site, producing long chain alkanes with a renewable diesel range. Attanatho (2012) had a 99.7\% conversion and $26.25 \%$ hydrodeoxygenation.

Understanding the importance of effective production of renewable diesel, research and development needs to be performed further. In this research, triolein was used as a model compound. Triolein with oleic acid as its fatty acid compound experiences hydrogenolysis to become fatty acid and fatty alcohol. Both are intermediate to produce long-chain alkanes with a selective deoxygenation process. Triolein was chosen because of its fatty acid composition, C18:1, which is the fatty acid of the highest composition in most vegetable oils. Moreover, using a model compound allows a thorough understanding of reaction pathways.

In this research, hydrodeoxygenation was carried out in a trickle bed reactor, which is a three-phase fixed bed reactor under a trickle flow regime. It has a lower pressure drop and higher conversion compared to other fixed bed reactor types. Compared to continuous stirred tanks, reactor trickle bed reactors do not require mechanical agitation so they consume less energy ( $\mathrm{Wu}$ and $\mathrm{Tu}, 2016)$. The hydrodeoxygenation of vegetable oil in a trickle bed reactor has the advantages of high production, easy process control, and no product separation from the catalyst. The drawback is the clogging of the catalyst pores for high concentrations of vegetable oil. Previous research on using trickle bed reactors for renewable diesel production using triolein has only been carried out by Muharam and Nugraha (2017) via simulation, which aimed to observe the optimum conditions in real practice for further improvement. The objective of the present research was to observe renewable diesel production based on triolein in a trickle bed reactor using a $\mathrm{NiMo} / \mathrm{Al}_{2} \mathrm{O}_{3}$ catalyst.

\section{Methods}

\subsection{Materials}

The main materials used were triglycerides, specifically triolein, and hydrogen gas. Triolein with $99 \%$ purity was dissolved in dodecane to achieve a composition of $5 \% \mathrm{w} / \mathrm{w}$. The NiMo $/ \mathrm{Al}_{2} \mathrm{O}_{3}$ catalyst with molybdenum as its active site is a commercial catalyst for hydrogenation in oil refineries. Sources of the materials used are listed in Table 1.

Table 1 Sources of Materials

\begin{tabular}{cll}
\hline No. & \multicolumn{1}{c}{ Material } & \multicolumn{1}{c}{ Source } \\
\hline 1 & Triolein & Jinan Chemicals, China \\
2 & Dodecane & Jinan Chemicals, China \\
3 & Hydrogen Gas & Indonesia \\
4 & NiMo $/ \mathrm{Al}_{2} \mathrm{O}_{3}$ Catalyst & Commercial Catalyst Company X \\
\hline
\end{tabular}


The catalyst was first characterized with Scanning Electron Microscope-Energy Dispersive Spectroscopy (SEM-EDS) to determine its composition. The catalyst was crushed and screened to have a spherical form of 0.85-1.00 mm diameter.

\subsection{Methods}

The reactor system is schematically illustrated in Figures 1 and 2. Seventy-one grams of the $\mathrm{NiMo} / \mathrm{Al}_{2} \mathrm{O}_{3}$ catalyst was put in a cylindrical reactor of $2.01 \mathrm{~cm}$ in diameter, which accounted for $24 \mathrm{~cm}$ of reactor bed height. The catalyst was activated by a hydrogen flowrate of $100 \mathrm{ml} / \mathrm{min}$ for 20 minutes under 5 bar pressure and $350^{\circ} \mathrm{C}$. Triolein from a liquid vessel and hydrogen from a gas cylinder were mixed and preheated by an electrical heater before entering the reactor. The isothermal reaction system was maintained by heating, using another electrical heater around the reactor bed. Liquid product sampling was carried out three times in a 5-minute interval, considering the reactor was operated continuously. The gaseous product was sampled directly from the downstream pipe using a syringe. These experiments were carried out at $272-327.5^{\circ} \mathrm{C}$ and 5 and 25 bars of pressure. The liquid samples were characterized using Gas Chromatography with FlameIonization Detection (GC-FID) for triglycerides, diglycerides, and monoglycerides, Karl Fischer for water, and Gas Chromatography-Mass Spectrometry (GC-MS) for other compounds, such as fatty acids, hydrocarbons, esters, and fatty alcohols. The gaseous product was characterized using Gas Chromatography -Thermal Conductivity Detector (GC-TCD).

The GC-FID used was Perkin Elmer Clarus 680, in the Chemical Engineering Department of the Universitas Indonesia, with a running time of 35 minutes, detector temperature of $380^{\circ} \mathrm{C}$, injection volume of $1 \mu \mathrm{L}$, and synthetic gas as a carrier. Triglyceride, diglyceride, and monoglyceride qualitative and quantitative tests were based on European Standard EN 14105. Meanwhile, the GC-MS used was also Perkin Elmer Clarus 680 for the GC, and Clarus SQ $8 \mathrm{~T}$ was the mass spectrometer. The method used was based on the FAME standard test with a run time of 51.5 minutes, temperature of $300^{\circ} \mathrm{C}$, injection volume of 1 $\mu \mathrm{L}$, and helium as a carrier. To detect and quantify water content, the Karl Fischer coulometric method was used. To detect propane and other gaseous products, GC-TCD GC8A Shimadzu was used. This was only to detect gaseous products, meaning no quantitative results were obtained.

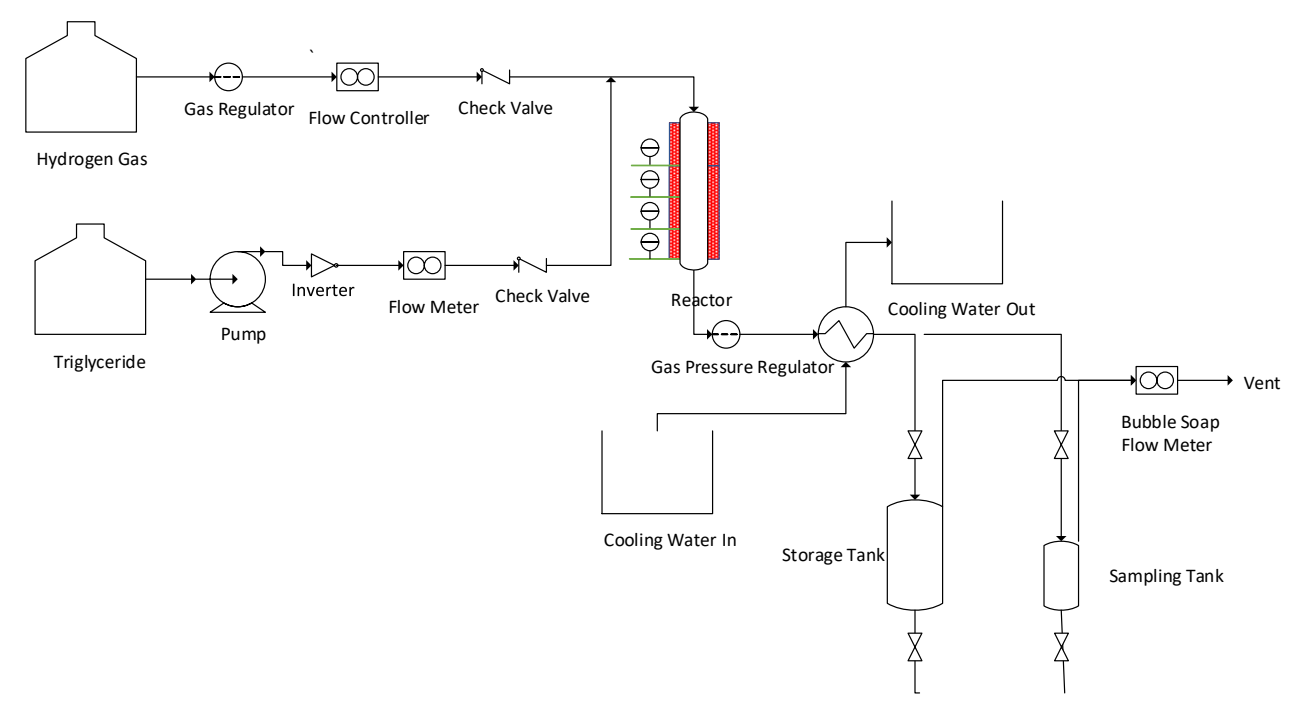

Figure 1 Experiment Setup, consists of: Hydrogen gas tank, Triglyceride tank, Gas regulator, Pump, Flow Controller, Check Valve, Inverter, Trickle bed reactor, Gas pressure regulator, Heat Exchanger with cooling water, Storage and sampling tank, Bubble soap flow meter, and Vent 


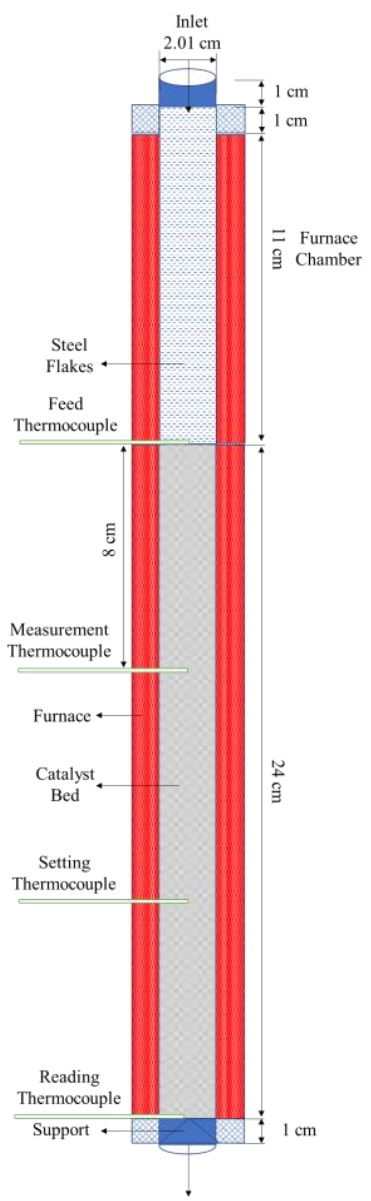

Figure 2 Reactor Scheme

\section{Results and Discussion}

The SEM-EDS results showed that the $\mathrm{NiMo} / \mathrm{Al}_{2} \mathrm{O}_{3}$ catalyst had a composition of $6.13 \%$ $\mathrm{w} / \mathrm{w} \mathrm{Ni}, 12.49 \% \mathrm{w} / \mathrm{w} \mathrm{Mo}$, and $81.33 \% \mathrm{w} / \mathrm{w} \mathrm{Al}_{2} \mathrm{O}_{3}$. This showed that the reactive site for this catalyst was molybdenum, which has proven to be effective for hydrodeoxygenation, thus, producing $\mathrm{C}_{18}$ (Susanto et al., 2016). Nickel is effective for decarboxylation and decarbonylation, which produce $\mathrm{C}_{17}$.

The proposed mechanism consisted of several reactions, as shown in equations $1-8$. At first, the triolein (TG or triglycerides) underwent hydrogenation and became free fatty acids (FFA) and diolein (DG or diglycerides). The diglycerides then were hydrogenated to become more free fatty acids (FFA) and monoolein (MG or monoglycerides). Monoglycerides were further converted to free fatty acids with hydrogenation, producing propane gas as a side product. Next, the free fatty acids were hydrogenated to become fatty alcohols, which was the raw material of the $\mathrm{C}_{18}$ hydrocarbon. This process is called hydrodeoxygenation, where fatty acid/fatty alcohol is converted to alkanes with the same carbon number. Hydrodeoxygenation produces water as a side product.

The remaining fatty acids also underwent decarbonylation and decarboxylation, producing $\mathrm{C}_{17}$ hydrocarbons. This process did not involve hydrogen but can be achieved under similar operating conditions. Decarbonylation and decarboxylation produce carbon monoxide and carbon dioxide, respectively. The last reaction that could happen is a reversible reaction, which involves co-existing fatty acids and fatty alcohols to become esters and water. Propane, carbon dioxide, and carbon monoxide were detected using GC- 
TCD. Meanwhile, the produced water was detected and measured using the Karl Fischer method.

$$
\begin{gathered}
\text { TG }+\mathbf{H}_{2} \stackrel{\text { k1 }}{\rightarrow} \mathbf{F F A}+\mathbf{D G} \\
\mathrm{DG}+\mathrm{H}_{2} \stackrel{\mathrm{k} 2}{\rightarrow} \mathrm{FFA}+\mathrm{MG} \\
\mathrm{MG}+\mathrm{H}_{2} \stackrel{\mathrm{k} 3}{\rightarrow} \mathrm{FFA}+\mathrm{C}_{3} \mathrm{H}_{8} \\
\mathrm{FFA}+2 \mathrm{H}_{2} \stackrel{\mathrm{k} 4}{\rightarrow} \mathrm{FA}+\mathrm{H}_{2} \mathrm{O} \\
\mathrm{FA}+\mathrm{H}_{2} \stackrel{\mathrm{k} 5}{\rightarrow} \mathrm{C} 18 \mathrm{HC}+\mathrm{H}_{2} \mathrm{O} \\
\mathrm{FFA} \stackrel{\mathrm{k} 6}{\rightarrow} \mathrm{C} 17 \mathrm{HC}+\mathrm{CO}_{2} \\
\mathrm{FFA}+\mathrm{H}_{2} \stackrel{\mathrm{k} 7}{\rightarrow} \mathrm{C} 17 \mathrm{HC}+\mathrm{CO}+\mathrm{H}_{2} \mathrm{O} \\
\mathrm{FA}+\mathrm{FFA} \stackrel{\mathrm{k} 8, \mathrm{k} 9}{\longrightarrow} \mathrm{ET}+\mathrm{H}_{2} \mathrm{O}
\end{gathered}
$$

(Source: Attanatho, 2012)

Figure 3 shows the concentrations of reacting compounds as a function of temperature and at 5 bar pressure. As can be seen in the figure, fatty acids were the dominant component. It reached more than $60 \% \mathrm{w} / \mathrm{w}$ at temperatures above $280^{\circ} \mathrm{C}$. The high concentration of monoglycerides indicates that its production rate from diglyceride is higher than its consumption rate, which is hydrogenation. The highest presence of fatty acids in liquid products was octadecanoic or stearic acid, a compound that has the same number of carbons as triolein. This acid does not have any double $\mathrm{C}$-C bonds, leading to the understanding that double bond saturation happens once the reactants mix. This complies with the proposed mechanism, stating that the initial step of the reactions is hydrogenation of unsaturated compounds.

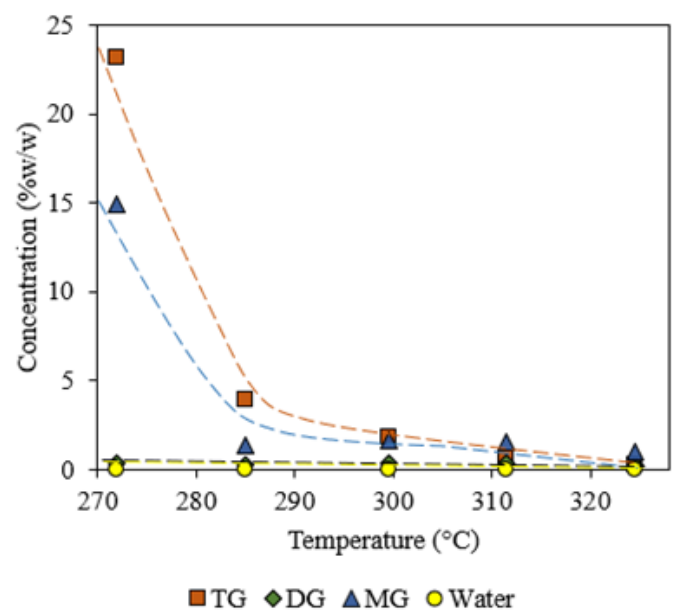

(a)

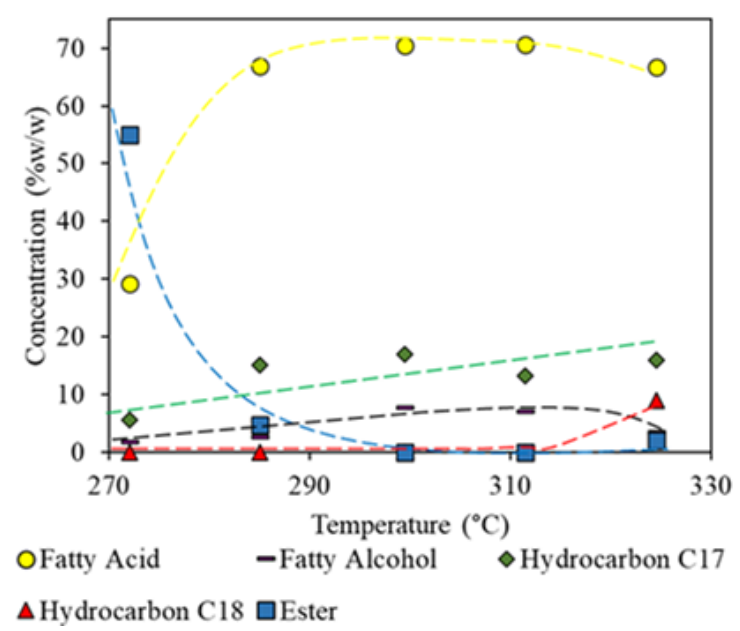

(b)

Figure 3 Reacting compounds at 5 bar: (a) triglyceride (TG), diglyceride (DG), monoglyceride (MG), and water; and (b) fatty acids, fatty alcohols, $\mathrm{C}_{17}$ hydrocarbons, $\mathrm{C}_{18}$ hydrocarbons, and esters

As can be seen in Figure $3 \mathrm{~b}, \mathrm{C}_{18}$ hydrocarbons only exist at the highest temperature, $324.5^{\circ} \mathrm{C}$, showing that at low pressure (as low as 5 bar), hydrodeoxygenation is not favored. This result is supported by data from Attanatho (2012), which says that the activation 
energy of the hydrodeoxygenation reaction is very high, reaching $129.4 \mathrm{~kJ} / \mathrm{mol}$. In addition, fatty acids have to be initially converted to fatty alcohols with an activation energy of 354.9 $\mathrm{kJ} / \mathrm{mol}$. In other words, the kinetic energy needed to overcome the high activation energy was only accomplished by the highest temperature of the experiments (i.e., $324.5^{\circ} \mathrm{C}$ ).

Figure 4 reveals the concentrations of reacting compounds as a function of temperature at 15 bar pressure. $\mathrm{C}_{18}$ hydrocarbons existed in all temperatures of experiments and became dominant reacting compounds at temperatures above $310^{\circ} \mathrm{C}$, which reached more than $50 \% \mathrm{w} / \mathrm{w}$. This indicated that high pressure supports hydrodeoxygenation. Some literature also reported that hydrodeoxygenation is favored under high pressure (Mortensen et al., 2014). The reason behind this phenomenon is that at high pressures, hydrogen solubility in dodecane is high, leading to a higher chance for reactants to contact and react.

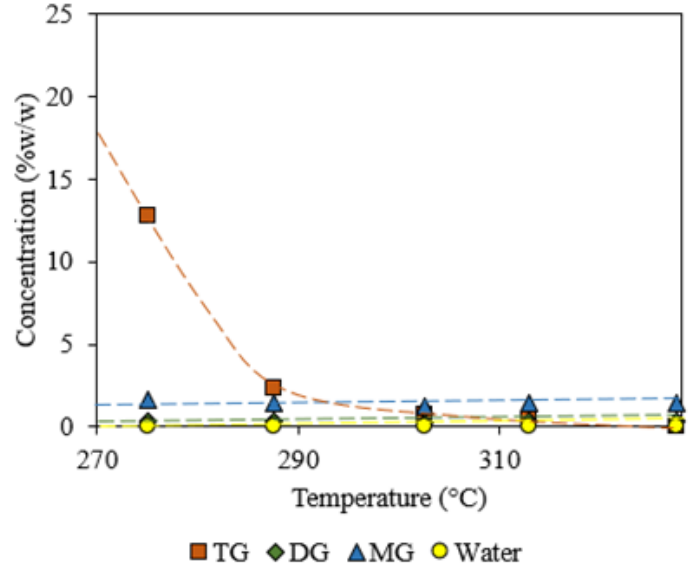

(a)

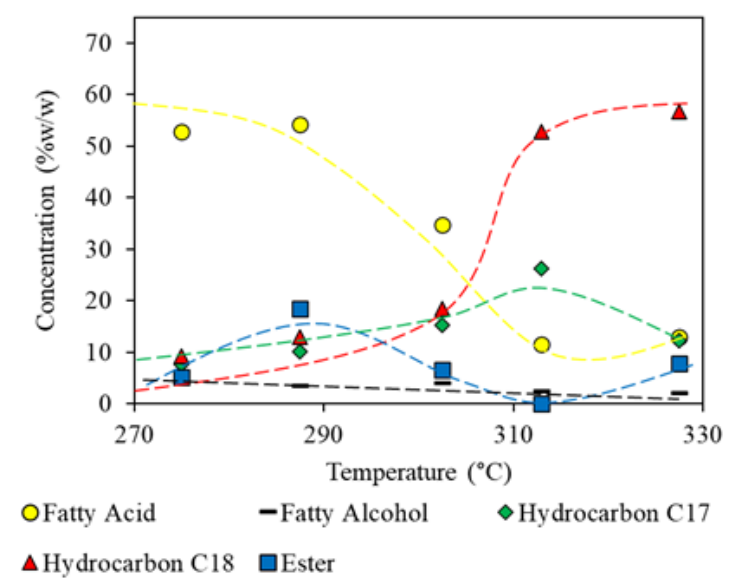

(b)

Figure 4 Reacting compounds at 15 bar: (a) triglyceride (TG), diglyceride (DG), monoglyceride (MG), and water; and (b) fatty acids, fatty alcohols, $\mathrm{C}_{17}$ hydrocarbons, $\mathrm{C}_{18}$ hydrocarbons, and ester

As the temperature increases, the fatty acid concentration decreases because fatty acids are converted to fatty alcohols and hydrocarbons, leading to an increase in the concentrations of $\mathrm{C}_{17}$ and $\mathrm{C}_{18}$ hydrocarbons. The material of $\mathrm{C}_{18}$ is fatty alcohols, formed after hydrogenation of free fatty acids. Meanwhile, the material of $\mathrm{C}_{17}$ is the free fatty acid itself. $\mathrm{C}_{18}$ hydrocarbons are more dominant than $\mathrm{C}_{17}$ hydrocarbons because the conversion rate of free fatty acids to fatty alcohols is faster compared to the conversion rate of free fatty acids to $\mathrm{C}_{17}$ hydrocarbons in favored conditions (Muharam and Putri, 2018). At the highest temperature, GC-MS results showed the existence of other compounds, such as $\mathrm{C}_{16}$ and $\mathrm{C}_{13}$ hydrocarbons, indicating the possibility of thermal cracking. The results also revealed that not all $\mathrm{C}_{18}$ hydrocarbons are octadecane. Several other isomers of $\mathrm{C}_{18}$ hydrocarbons appeared (i.e., 4-methyl heptadecane, 3-methyl heptadecane, and 8-methyl heptadecane). Isomerization and cracking mechanisms were confirmed in several articles, for example, in the research results of Veriansyah et al. (2012).

Ayodele et al. (2014) stated that temperature highly affects hydrodeoxygenation. Their research results showed similar trends to this research in that the renewable diesel yield, selectivity, and purity slightly decreased with increasing temperatures. Thermal cracking is believed to be the cause of the formation of lower hydrocarbons at higher temperatures. In general, high conversion and renewable diesel yield, selectivity, and purity were obtained at 15 bar. This indicates that renewable diesel production is preferred at higher pressure. In addition, the research also determine the pressure effect toward the reaction 
extent for oleic acid hydrodeoxygenation above a nickel molybdenum catalyst. That research showed an increase in the $\mathrm{C}_{18}$ hydrocarbon yield from low to high pressures, reaching a peak at 20 bar, and decreasing as pressure further increased. Heriyanto et al. (2018) performed research at high pressures, above 20 bar. The yield obtained also decreased with increasing pressure. This happens because very high pressures complicate target fractions to remove catalyst surfaces. Tóth et al. (2011) confirmed this argument, since their research results showed that as the pressure increased, the oxygenate yield rose and the renewable diesel yield was reduced. Based on this fact, the use of 15 bars on the hydrodeoxygenation of vegetable oils is neither too high nor too low to produce renewable diesel. A pressure of around 15 bars increased the solubility of hydrogen gas in liquid phases. As a result, the dissolved hydrogen was able to overcome the mass transfer resistance in bulk liquids. The highest resistance of mass transfer was in the bulk liquid.

\section{Conclusions}

Hydrodeoxygenation of vegetable oil represented by triolein for renewable diesel production was investigated in a trickle bed reactor of $2.01 \mathrm{~cm}$ in diameter and $24 \mathrm{~cm}$ in bed length. $\mathrm{C}_{18}$ hydrocarbons became dominant reacting compounds at temperatures above $310^{\circ} \mathrm{C}$ and a pressure of 15 bar, which reached more than $50 \% \mathrm{w} / \mathrm{w}$. At 5 bar pressure, fatty acids with stearic acid as the acid with the highest concentration were the dominant reacting component, reaching more than $60 \% \mathrm{w} / \mathrm{w}$ at temperatures above $280^{\circ} \mathrm{C}$. This led to double bond saturation once the reactants mixed.

\section{Acknowledgements}

We express our gratitude to Universitas Indonesia, which funded this research through the scheme of Publikasi Terindeks Internasional (PUTI) Prosiding Tahun Anggaran 2020 Nr NKB-1194/UN2.RST/HKP.05.00/2020.

\section{References}

Attanatho, L., 2012. Performances and Kinetic Studies of Hydrotreating of Bio-Oils in Microreactor. Master's Thesis, Graduate Program, Oregon State University, Corvallis, United States of America

Ayodele, O.B., Abbas, H.F., Daud, W.M.A.W., 2014. Catalytic Upgrading of Oleic Acid into Biofuel using Mo Modified Zeolite Supported Ni Oxalate Catalyst Functionalized with Fluoride Ion. Energy Conversion and Management, Volume 88, pp. 1111-1119

Bezergianni, S., Dimitriadis, A., 2013. Catalytic Hydrotreating of Waste Cooking Oil for Renewable Diesel Production. In: Proceedings of the $9^{\text {th }}$ International Colloquium on Fuels Conventional and Future Energy for Automobiles, Ostfildern, Germany

Douvartzides, S.L., Charisiou, N.D., Goula, M.A., Papageridis, K.N., 2019. Green Diesel: Biomass Feedstocks, Production Technologies, Catalytic Research, Fuel Properties and Performance in Compression Ignition Internal Combustion Engines. Energies, Volume 12(5), pp. 1-4

Gong, S., Shinozaki, A., Shi, M., Qian, E.W., 2012. Hydrotreating of Jatropha Oil over Alumina Based Catalysts. Energy and Fuels, Volume 26(4), pp. 2394-2399

Heriyanto, H., Murti, S., Heriyanti, S.I., Sholehah, I., Rahmawati, A., 2018. Synthesis of Green Diesel from Waste Cooking Oil through Hydrodeoxygenation Technology with $\mathrm{NiMo} / \mathrm{Y}$ $\mathrm{Al}_{2} \mathrm{O}_{3}$ Catalysts. MATEC Web of Conferences, Volume 156, pp. 1-6

Holmgren, J., 2007. Green Diesel Production from Vegetable Oil. In: 2007 Spring AIChE Conference, Houston, United States of America 
Kubička, D.., Vik, J., Bejblová, M., 2010. Conversion of Vegetable Oils into Hydrocarbons over CoMo/MCM-41 Catalysts. Topics in Catalysis, Volume 53, pp. 168-178

Mortensen, P.M., Gardini, D., Carvalho, W.P.D., Damsgaard, C.D., Grunwaldt, J., Jensen, P.A., Wagner, J.B., Jensen, A.D., 2014. Stability and Resistance of Nickel Catalysts for Hydrodeoxygenation: Carbon Deposition and Effects of Sulfur, Potassium, and Chlorine in the Feed. Catalysis Science \& Technology, Volume 4, pp. 3672-3686

Muharam, Y., Nugraha, O.A., 2017. Prediction of the Effects of the Inlet Velocity and the Reactor Length on the Performance of a Trickle-Bed Reactor for Renewable Diesel Production. Journal of Computational and Theoretical Nanoscience, Volume 23(6), pp. 5609-5614

Muharam, Y., Putri, A.D., 2018. Simulation of Hydrotreating of Vegetable Oil in a Slurry Bubble Column Reactor for Green Diesel Production. International Journal of Technology, Volume 9(6), pp. 1168-1177

Pinzi, S., Dorado, M.P., 2012. Feedstocks for Advanced Biodiesel Production. In: Advances in Biodiesel Production, Woodhead Publishing, York, North Yorkshire, United Kingdom, pp. 69-90

Setiawan, E.A., Asvial, M., 2016. Renewable Energy's Role in a Changing World. International Journal of Technology, Volume 7(8), pp. 2087-2100

Susanto, B.H., Prakasa, M.B., Nasikin, M., Sukirno, S., 2016. Synthesis of Renewable Diesel from Palm Oil and Jatropha Curcas Oil through Hydrodeoxygenation using NiMo/Zal. International Journal of Technology, Volume 7(8), pp. 1405-1412

Tóth, C., Baladincz, P., Kovács, S., Hancsók. J., 2011. Producing Clean Diesel Fuel by Cohydrogenation of Vegetable Oil with Gas Oil. Clean Technologies and Environmental Policy, Volume 13, pp. 581-585

Veriansyah, B., Han, J.Y., Kim, S.K., Hong, S.A., Kim, Y.J., Lim, J.S., Shu, Y.W., Oh, S.G., Kim, J., 2012. Production of Renewable Diesel by Hydroprocessing of Soybean Oil: Effect of Catalysts. Fuel, Volume 94, pp. 578-585

Wu, C., Tu, X., 2016. Biological and Fermentative Conversion of Syngas. In: Handbook of Biofuels Production, pp. 335-357. Edited by Rafael Luque, Carol Sze Ki Lin, Karen Wilson and James Clark 